\title{
BATATA YACON: CARACTERIZAÇÃO E INATIVAÇÃO ENZIMÁTICA
}

\author{
A. P. BERTOLO ${ }^{1}$ \\ ${ }^{1}$ Universidade do Estado de Santa Catarina \\ E-mail para contato: angelica_bertolo@hotmail.com
}

\begin{abstract}
RESUMO - É notável o crescente interesse da população em consumir alimentos mais saudáveis, relacionando dieta, saúde e bem-estar. Os alimentos funcionais ou nutracêuticos como, por exemplo, a batata yacon (Polymnia sonchifolia), além de suas funções nutricionais normais, também é capaz de melhorar as condições de saúde do consumidor, podendo prevenir o surgimento de determinadas doenças degenerativas. $\mathrm{O}$ objetivo do presente trabalho foi caracterizar físico-quimicamente esse tubérculo, além de avaliar parâmetros para sua inativação enzimática. Em sua composição a batata yacon apresentou elevado conteúdo de umidade $(86,89 \mathrm{~g} / 100 \mathrm{~g})$ e carboidratos totais $(14,04 \mathrm{~g} / 100 \mathrm{~g})$, podendo ser considerada também uma boa fonte de fibra bruta $(3,28 \mathrm{~g} / 100 \mathrm{~g})$ e uma fonte pobre de proteínas $(0,43 \%)$, cinzas $(0,35 \%)$ e lipídeos $(0,15 \%)$. A enzima peroxidase é encontrada em vários alimentos, inclusive na batata yacon, sendo responsável por catalisar alterações de oxidação de compostos fenólicos levando ao aparecimento de pigmentos escuros. Vários métodos físicos e químicos são propostos para o controle dessa reação. $\mathrm{O}$ uso de compostos antioxidantes apresenta-se como uma das principais alternativas, tendo em vista sua facilidade e fator econômico. Neste trabalho foram testadas diferentes concentrações de ácido ascórbico, qual se mostrou eficiente em baixas concentrações.
\end{abstract}

Palavras-chave: alimentação saudável, composição, escurecimento enzimático

DOI: $10.5965 / 24473650312017007$

\section{INTRODUÇÃO}

A demanda do mercado atual está direcionada a produtos com elevado valor nutricional e que desempenham efeito benéfico à saúde do consumidor. A batata yacon (Polymnia sonchifolia) é considerada um alimento funcional, capaz de ajudar no controle de diabete, regulação intestinal, redução do colesterol, aumento da imunidade e aumento da absorção de minerais como cálcio, magnésio e ferro (QUINTEROS, 2000). Estes benefícios são oriundos de antioxidantes, compostos fenólicos e fruto-oligossacarídeos, componentes representativos neste tubérculo.

A batata yacon também possui polifenóis em sua composição, que podem causar sabor adstringente e também favorecer o escurecimento enzimático (QUINTEROS, 2000), por isso, técnicas que amenizem esses fatores adversos devem ser realizadas. 
Para fins práticos, o controle do escurecimento enzimático é geralmente limitado à inibição das enzimas - polifenoloxidase (PPO) e peroxidase (POD), responsáveis pela reação de escurecimento (MOURA, 2004).

Além das alterações na pigmentação, POD também induz alterações negativas de sabor durante a estocagem, sendo capaz de catalisar um grande número de reações oxidativas (MOURA, 2004). Por este motivo, a utilização da yacon em sua forma processada (farinha, chá, bebida e outros) ou como componente de algum outro produto alimentício, requer um estudo em relação à inativação enzimática, que seja capaz de evitar estas alterações.

De maneira geral, o controle do escurecimento enzimático pode ser feito através de métodos físicos e/ou químicos. Os métodos físicos incluem redução de temperatura ou inativação térmica da enzima, proteção do produto contra oxigênio, desidratação, uso de atmosfera modificada, embalagens ativas e outros. Os métodos químicos envolvem o uso de compostos antioxidantes (ácido ascórbico, cítrico e outros) que inibem a ação da enzima (OLIVEIRA et al., 2008).

O objetivo do presente trabalho foi caracterizar físico quimicamente a batata yacon e avaliar a eficiência de um tratamento combinado para a inibição da atividade enzimática.

\section{METODOLOGIA}

\subsection{Caracterização da batata yacon}

Os teores de umidade, proteína bruta, lipídeos, cinzas e fibras da yacon in natura foram analisados de acordo com as metodologias descritas pelo Instituto Adolfo Lutz (2008). O teor de carboidratos totais foi obtido por diferença. Todas as análises foram realizadas em triplicata.

\subsection{Processamento da batata yacon}

A batata yacon foi obtida em comércio local (Laranjeiras do Sul - Paraná). Sua caracterização física foi realizada imediatamente após sua recepção: cores interna e externa, dimensões e defeitos. A Figura 1 apresenta as etapas de processamento da batata yacon.

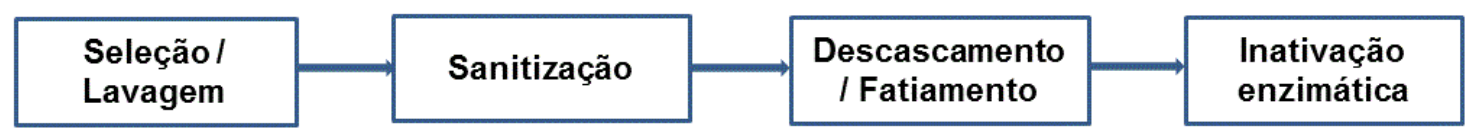

Figura 1 - Fluxograma do processamento da batata yacon

A lavagem da batata yacon foi realizada em água corrente, seguida da etapa de sanitização com imersão em água clorada a 50 ppm por 15 min, enxágue e descascamento.

$\mathrm{Na}$ sequência foi realizado o fatiamento em processador de alimentos (SKYMSEN, PA-7SE-N) com lâmina de $3 \mathrm{~mm}$ de espessura.

\subsection{Inativação enzimática}


A inativação enzimática foi realizada por técnica de branqueamento, combinando-se tratamento térmico e químico. Após ensaios preliminares foram testadas duas concentrações de ácido ascórbico $(0,5$ e $1,0 \%)$ em solução aquosa durante 5 min em água a $80{ }^{\circ} \mathrm{C}$, e após resfriadas em temperatura ambiente.

\section{RESULTADOS}

\subsection{Caracterização da batata yacon}

Os valores obtidos para a composição físico-química da batata yacon in natura são apresentados na Tabela 1, juntamente com os desvios relacionados.

Tabela 1 - Composição centesimal do Yacon in natura (em base úmida)

\begin{tabular}{c|c}
\hline Componentes & $\mathbf{g} / \mathbf{1 0 0 g}$ \\
\hline Umidade & $86,89 \pm 0,87$ \\
Fibra bruta & $3,28 \pm 0,16$ \\
Proteína bruta & $0,43 \pm 0,02$ \\
Cinzas & $0,35 \pm 0,05$ \\
Lipídios & $0,15 \pm 0,05$ \\
Carboidratos totais & 14,04 \\
\hline
\end{tabular}

A Tabela 2 apresenta a composição físico-química encontrada nesta pesquisa da yacon in natura (em base seca) juntamente com os valores obtidos por outros pesquisadores, para comparação.

Tabela 2 - Comparação da composição centesimal do yacon in natura (BS)

\begin{tabular}{ccccc}
\hline COMPOSIÇÃO & VALORES & NIETO, & VILHENA, & MARANGONI, \\
$(\boldsymbol{\%})$ & ${\text { Média }( \pm \mathbf{D P})^{(\mathbf{1})}}^{\text {Mén }}$ & $\mathbf{1 9 9 1}$ & $\mathbf{2 0 0 0}$ & $\mathbf{2 0 0 7}$ \\
\hline Sólidos totais & $13,11( \pm 0,87)$ & n.c $^{(2)}$ & n.d & 12,55 \\
Fibra bruta & $25,02( \pm 1,19)$ & 3,4 & 3,26 & 22,97 \\
Cinzas & $3,74( \pm 0,19)$ & 3,5 & 3,56 & 2,84 \\
Proteína bruta & $3,31( \pm 0,12)$ & 3,7 & 4,34 & 1,02 \\
Lipídios & $1,11( \pm 0,41)$ & 1,5 & 1,66 & 0,52 \\
Carboidratos totais & 78,73 & n.c & n.d & 95,44 \\
pH* & $6,57( \pm 0,28)$ & n.c & 5,53 & 6,38 \\
\hline
\end{tabular}

${ }^{(1)}$ desvio-padrão; ${ }^{(2)}$ não citado; ${ }^{(3)}$ não determinado; * em base úmida

A batata yacon, assim como outros tubérculos, possui elevado teor de umidade, qual se mostrou equivalente a $86,89 \%( \pm 0,87)$ neste estudo, próximo ao valor encontrado por Marangoni $(2007)$ que foi de $87,45 \%$. Devido seu elevado teor de umidade, o conteúdo em matéria seca torna-se bastante inferior e sua taxa de degradação aumenta.

Os carboidratos totais apresentaram-se como os componentes majoritários, representando 78,73 $\%$ da massa seca. O resultado obtido foi inferior ao valor encontrado por Marangoni (2007). 
O percentual de fibra encontrado neste estudo foi equivalente a 25,02 \% $( \pm 1,19)$, próximo do valor obtido por Marangoni (2007) de 22,97\%.

O percentual de resíduo mineral fixo obtido neste estudo foi de 3,74 \% $( \pm 0,19)$, similar aos valores encontrados por Nieto (1991) de 3,5 \% e Vilhena et al., (2000) de 3,56\%.

O teor de proteína é o componente que apresentou maior variação entre os autores pesquisados. Neste estudo, o percentual médio de proteína foi de $3,31 \%( \pm 0,12)$, semelhante ao valor obtido por Nieto (1991) de 3,7\%.

O percentual de gordura equivalente a $1,11 \%( \pm 0,41)$ também se mostrou próximo ao valor obtido por Nieto (1991) de 1,5\% e Vilhena et al., (2000) de 1,66\%.

A análise de $\mathrm{pH}$ resultou em $6,57( \pm 0,28)$, levemente superior ao valor encontrado por Marangoni (2007) de 6,38.

A partir dos resultados obtidos nas análises e comparando-se com a Tab. 2, é possível verificar que a composição da yacon varia de maneira significativa. Essa variação pode ser justificada pela variação climática, localidade e condições do plantio (solo), bem como pelo período e condições de plantio e de colheita.

\subsection{Inativação enzimática}

$\mathrm{O}$ vegetal imerso em solução contendo ácido ascórbico $0,5 \%$ durante 5 min à $80{ }^{\circ} \mathrm{C}$ sofreu oxidação (fenóis a quinonas) e, consequente, escurecimento durante o armazenamento (refrigerador $10{ }^{\circ} \mathrm{C}$ ). As fatias de yacon que foram branqueadas em solução contendo $1,0 \%$ de ácido ascórbico não sofreram alteração da cor durante o armazenamento, indicando que essa concentração de ácido é mais efetiva para a inativação enzimática neste tipo de produto.

A solução aquosa com $0,5 \%$ de ácido ascórbico apresentou aumento do pH com a adição do produto, o que resultou em uma inativação enzimática não satisfatória. A reposição contínua do ácido na solução pode aumentar a eficiência da inativação enzimática utilizando esta concentração, mas a necessidade do rígido controle do $\mathrm{pH}$ dificulta o emprego desta concentração na prática.

No estudo para comparação de diferentes métodos de inativação enzimática, Souza e Leão (2012) avaliaram diferentes métodos: redução do pH, remoção de oxigênio e calor. Dentre estas metodologias, a que se mostrou mais eficiente foi o método químico - uso de agentes acidificantes (redução do pH). Avaliaram-se soluções de ácido: ascórbico 1,0 \%, cítrico 1,0 \% e acético em concentração de $0,1 \%$ e $1,0 \%$. Entre os diferentes agentes, o ácido ascórbico 1,0 \% foi o que obteve maior eficiência na inativação enzimática de maçã, banana, batata e cenoura.

O ácido ascórbico (vitamina C) e seus sais neutros são reconhecidos por sua ação redutora, sendo considerados como os principais antioxidantes para o uso em frutas, hortaliças e seus sucos. $\mathrm{O}$ ácido ascórbico atua sequestrando o cobre, grupo prostético da PPO, e reduzindo as quinonas de volta a fenóis, antes de formarem pigmentos escuros (COSTA, 2010).

\section{CONCLUSÕES}

A batata yacon destaca-se em função de seus benefícios nutricionais e funcionais ao organismo humano. Apresenta elevado conteúdo de carboidratos, sendo esses representados em sua maioria por fruto-oligossacarídeos (FOS) e inulina. 
Seu principal constituinte é a água, o que a torna suscetível a uma rápida degradação e a uma vida útil, em condições ambientais, bastante reduzida. Devido a presença de polifenóis em sua composição técnicas que amenizem o escurecimento enzimático devem ser realizadas. Recomenda-se o tratamento combinado de inativação enzimática em solução de ácido ascórbico $1 \%$ à $80{ }^{\circ} \mathrm{C}$ por 5 minutos.

\section{REFERÊNCIAS}

COSTA, A.C. Estudo da conservação do pêssego (Prunus persica L.) minimamente processado. 2010. 79 f. Tese (Doutorado em Ciência e Tecnologia Agroindustrial) Universidade Federal de Pelotas, Pelotas, 2010.

INSTITUTO ADOLFO LUTZ. Métodos físico-químicos para análise de alimentos. 1 Ed digital. Versão eletrônica./coordenadores Odair Zenebon, Neus Sadocco Pascuet e Paulo Tiglea -- São Paulo, Brasil: IMESP, 2008.

MARANGONI, A. L. Potencialidade de aplicação de farinha de Yacon (Polymnia sonchifolia) em produtos à base de cereais. Campinas, Brasil: [s.n], 2007.

MOURA, C. P. Aplicação de redes neuronais para a predição e otimização do processo de secagem de yacon (Polymnia sonchifolia) com pré-tratamento osmótico. 2004. 115 f. Dissertação de (Mestrado em Tecnologia de Alimentos), Universidade Federal do Paraná, Curitiba, 2004.

NIETO, C.C. Estudios agronómicos y bromatológicos en jicama (Polymnia sonchifolia Poep et Endl.). Archivos Latinoamericanos de Nutrición, v. 41, p. 213-221, 1991.

OLIVEIRA, T.; SOARES, N. F.; PAULA, C.; VIANA, G. A. Uso da embalagem ativa na inibição do escurecimento enzimático de maçãs. Ciências Agrárias, Londrina, v. 29, p. 117-128, 2008.

QUINTEROS, E. T. Produção com tratamento enzimático e avaliação do suco de yacon. Campinas, Brasil: [s.n], 2000.

SOUZA, A.; LEÃO, M. Análise dos métodos mais eficientes na inibição do escurecimento enzimático em frutas e hortaliças. Enciclopédia biosfera, Centro Científico Conhecer, Goiânia, v. 8, p. 117, 2012.

VILHENA, S. M. C.; CÂMARA, F. A.; KAKIHARA, S. T. O cultivo de yacon no Brasil. Horticultura Brasileira, Brasília, v. 18, p. 5-8, 2000. 